\title{
Anaerobic Digestion in the Nexus of Energy, Water and Food
}

\author{
Nikolaos Voulvoulis \\ Centre for Environmental Policy, Imperial College London, London SW7 2AZ, UK
}

Received: January 26, 2015 / Accepted: March 02, 2015 / Published: May 31, 2015.

\begin{abstract}
Conventional waste management practices focusing principally on waste collection, treatment and disposal or even minimisation often prove insufficient to address resource management challenges in a sustainable manner. Taking into account the relationship between water provision, energy security and resource efficiency, a systems approach that delivers a strong information basis and provides opportunities for resource use optimisation at various levels of application provides opportunities for synergies that could deliver real benefits when cross-sectoral solutions are applied. By-products from sewage treatment in combination with organic solid waste such as food waste can provide a valuable source of energy if managed properly and utilised effectively. This way, waste can be seen as a raw material than can be turned into a resource rather than simply be discarded. As such, AD (anaerobic digestion), the co-digestion of food waste with sewage sludge, could become a strategic and cross-sectoral solution, if carefully applied, with the potential to convey beneficial synergies for the water and the waste industries. However, barriers to the development of such systems are diverse and often interlinked. Institutional frameworks, decision making constraints, and regulatory boundaries might still appear to require an answer for three different problems, but this can be overcome if presented as just three different parts of the same answer. Such synergies could deliver economic benefits from the additional renewable energy generated and its associated incentives, and savings on costs for the infrastructure required for the exclusive digestion of food waste.
\end{abstract}

Key words: Waste management, energy-water-food nexus, systems thinking, anaerobic digestion.

\section{Introduction}

One of the most profound causes of waste generation is the way in which traditional production and consumption processes have been so entirely linear. While in the past, such processes were perhaps considered "efficient", when considering the whole life costs of production, it is hard to demonstrate a real benefit for these practices [1]. Similarly, the introduction of environmental management systems and clean production in industry in recent years, driven by more preventive approaches, mainly seeks to minimise waste and increase resource efficiency, thus, overlooking opportunities that lie across sectors, or in linking both ends of the chain.

Environmental management systems and clean

Corresponding author: Nikolaos Voulvoulis, Dr., research field: environmental management and policy. E-mail: n.voulvoulis@imperial.ac.uk. production applications in recent years have increased the environmental performance of industrial establishments and sectors and have also affected the economic performances and corporate prestige in a positive way. However, such initiatives are often constrained within the borders of firms or sectors and are driven by more preventive approaches, which mainly seek-for each production process-to minimise the generation of waste and increase resource efficiency. This has the drawback of overlooking opportunities that lie across sectors, or that could link both ends of the chain [1].

Taking into account the relationship between water provision, energy security and resource efficiency, waste and environmental challenges - often too complex to address-provide opportunities for synergies that could deliver real benefits when cross-sectoral solutions are applied. Conventional 
waste management approaches focusing principally on waste collection, treatment and disposal or even minimisation often prove insufficient to address resource management challenges sustainably [2]. It is essential to focus on a systems analysis approach using information to identify opportunities for resource use optimisation at various levels of application.

This paper considers anaerobic digestion as a waste management option and reflects on the scenarios and calculations that evaluate its potential as an integral part of wider sustainable resource management, with a renewed focus on its role from a systems perspective.

\section{AD (Anaerobic Digestion)}

$\mathrm{AD}$ involves a series of processes in which microorganisms break down biodegradable material in the absence of oxygen. AD converts organic matter into biogas (consisting primarily of methane and carbon dioxide), a renewable source of energy, and digestate, a potentially valuable fertiliser and soil conditioner, and was originally used in the treatment of sewage sludge and agricultural manure and slurry [3]. Currently, it is commonly practiced in MSW (municipal solid waste) management throughout Europe. MSW is a heterogeneous waste stream that requires pre-treatment and post-treatment to digest. For this reason, AD facilities extend beyond the biochemical reactions and include a series of processes that involve the collection, pre-treatment, digestion, and digestate post-treatment of MSW that are often not properly accounted for or understood in policy making [4]. Depending on the MSW fractions and processes employed, AD produces biogas and digestate which may be appropriate for application to land or disposal as treated waste (Fig. 1).

In the UK, $\mathrm{AD}$ has gained momentum in policy and policy making over the last years as a promising technology both as a MSW management option and a highly sustainable energy alternative. Total installed capacity in the UK in 2011 was found to be around $700,000 \mathrm{t}$ with an average installed capacity of approximately $64,000 \mathrm{t}$. A number of incentives have been introduced to encourage the uptake of $\mathrm{AD}$ due to its potential to assist with the EU and national targets on waste management, renewable energy generation and reduction of carbon emissions [3]. Such incentives include: FITs (feed-in tariffs), for small-scale renewable electricity generation producers of up to 5 MWe; ROCs (renewable obligation certificates), for large-scale renewable electricity generation (>5 MWe); RHTs (renewable heat tariffs), for heat used from biogas combustion in CHP (combined heat and power) $(>1,000 \mathrm{kWth})$ and the installation of a renewable heat system depending on the produced heat, type of technology and size of the system; and RTFO (renewable transport fuels obligation), for ensuring that a specified percentage of the total supply of road transport fuel originates from a sustainable and renewable source [3]. All fuel suppliers of at least $450,000 \mathrm{~L}$ of fuel a year are obligated; there are LEC (levy exemption certificates), for providing evidence of electricity supply generated from qualifying renewable sources that is exempt from the climate change levy [5]. In addition, a plethora of guidance and protocols has been introduced in the UK to improve the quality of the digestate produced in order to ensure its marketing

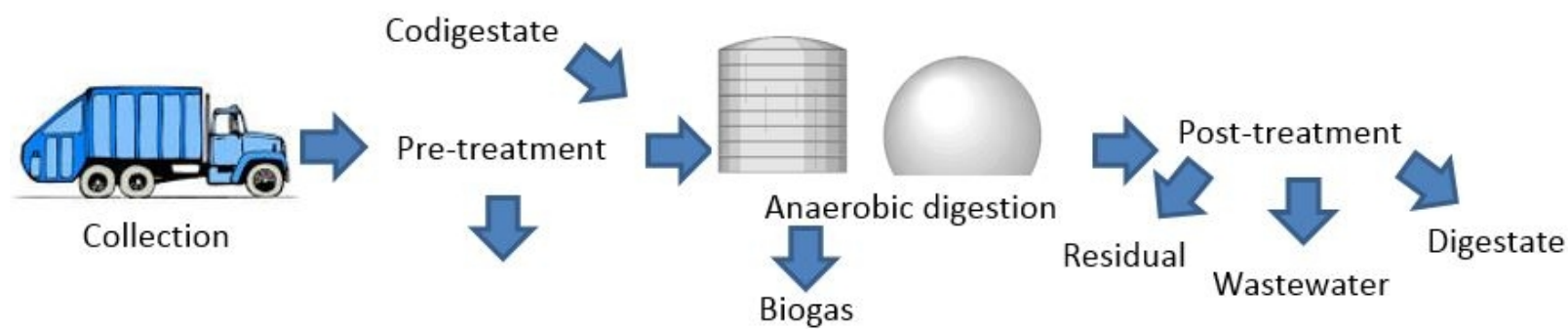

Fig. 1 Anaerobic digestion of MSW as a series of physical, chemical and biological processes that involve the collection, pre-treatment, digestion, and post-treatment of single stream or co-digested fractions of MSW to produce biogas and digestate. 
potential [4]. Despite these initiatives, the implementation of AD for the treatment of MSW has been hampered.

Technical, operational, economic and regulatory constraints related to the $\mathrm{AD}$ process as a whole have slowed its uptake and application by the UK market. In addition increasing concerns regarding the reliability of food waste digestion have led to the investigation of its co-digestion with sewage sludge as an alternative [3]. At the same time, it is widely recognised that water treatment and distribution and wastewater treatment processes are very energy intensive, and could benefit from any initiatives that help in this area $[6,7]$.

\section{In the Context of a Resource Economy}

In the traditional version of the modern economy, natural resources are mined and extracted, turned into products and finally discarded, with the traditional development model driven by heavy industrial growth and resource-intensive infrastructure. This remains a fundamentally open, linear system, and one that is likely to cause unsustainable pressures on the environment [8]. Rather than releasing high quality waste back into the environment while simultaneously paying to extract it as minerals through traditional mining of raw materials, it is more sustainable and energy efficient to close the loop (Fig. 2) [1]. Resource reuse can help to close the loop between supply and waste disposal, providing a sustainable alternative to the extraction of virgin stocks. Given the dual need to protect the environment and recognise the importance of natural capital, while at the same time, enhancing our economic prosperity and improving living standards of developing countries and the world's poor, achieving more from less by closing the resource loops is of paramount importance.

Properly accounting for natural capital in resources management first requires a more comprehensive understanding of the use and disposal of materials and their waste by-products, including those produced through resource extraction, material processing, product

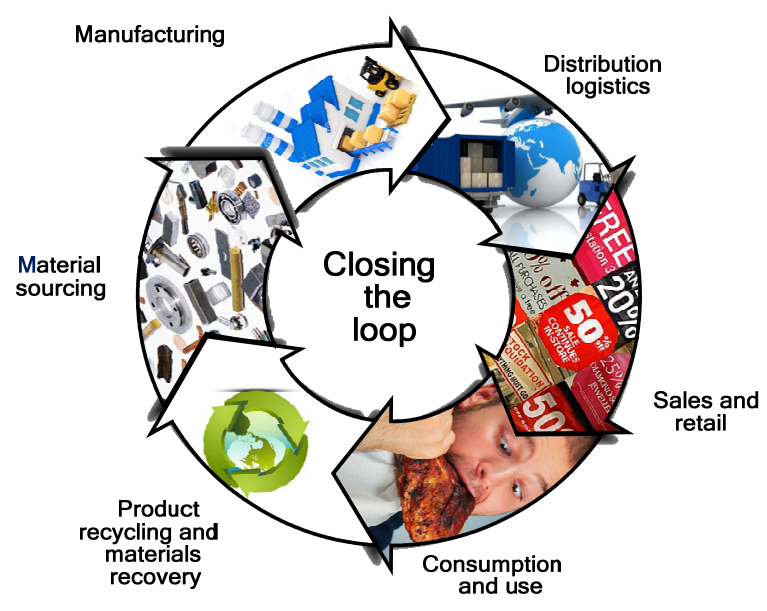

Fig. 2 Closing the loop: sustainable resources management.

design and manufacturing, and of how products are consumed and move towards their end-of-life cycle [9]. Economies are largely dependent on linear systems where resources are extracted from virgin stocks before ending up as discarded waste after proceeding through a supply chain which itself produces waste at every stage [10]. While, the debate surrounding "peak minerals" and the potential threat posed by resource scarcity is ongoing [11-15], it is nevertheless essential to address the inefficiencies of this system, especially when social and environmental constraints are taken into account in addition to physical ones [16] (Fig. 3). Despite ongoing arguments on the availability of abundant geologic resources, it is still ethically responsible to manage properly all associated environmental, economic and social impacts associated with any increases in production [17].

\section{Discussion}

The nexus of water, energy and materials is slowly becoming recognised as a system that needs to be examined, but solutions have so far not been nearly integrated enough to deliver overall benefits across the sectors, especially in view of the many emerging challenges facing resources management [1]. Rising global demand for energy and materials will also 
increase our impact on water resources, a trend exacerbated by these facts: that mining activities are increasingly taking place in water scarce regions, that climate change presents further challenges in terms of water scarcity, and that globally declining ore grades for many major commodities are likely to increase water demands for most future mines [18]. Meeting the growing demand for commodities will of course also bring additional demand for energy used in extraction, processing and transport, while, it is additionally evident that, material constraints could have an impact on the sustained growth of the renewable energy sector [19-21].

While, it has been often accepted that, it is the responsibility of governments to impose solutions upon resource users in the form of regulation in order to achieve sustainable resource use, certain government policies have been shown to accelerate resource destruction. At the same time, some resource users have seen the benefits of investing in sustainable practices [22]. Achieving this sustainability, however, requires our many ecological/environmental, economic and social issues to be accounted for (Fig. 4). A better understanding of demand and pressure on the existing resources, followed by appropriate pricing that is inclusive of all environmental costs, can light up the way for new opportunities for resource recovery through waste management.

It is essential to use appropriate pricing that is inclusive of all environmental costs and environmental externalities when making decisions and developing policies relating to the use of raw materials (e.g., from the mining sector) versus recycled materials from the waste sector. The carrying capacity of the natural environment is an unprized input to resource production, and it is increasingly accepted that, resource users should be made to pay for the environmental impacts they cause [23]. While, several methods for the monetary valuation of environmental impacts have been developed [24], the internalisation of environmental costs has yet to become fully mainstream in practice [25].

In addition, in light of increasing concerns regarding material security, shortages and environmental pollution, realistic frameworks have emerged for processing waste as a resource in many parts of the world [26-28]. More broadly, waste recycling and reuse can provide a viable opportunity to augment traditional resource supplies, at the same time reducing the need for waste disposal [29].

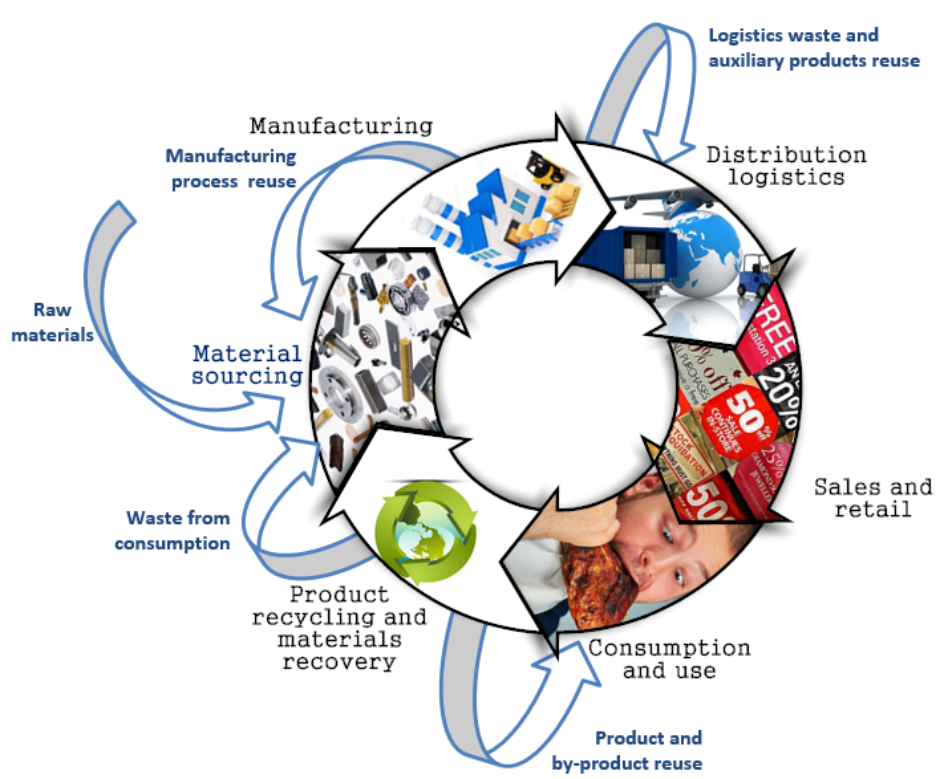

Fig. 3 Industrial symbiosis as a closed loop value chain, where manufacturers are able to capture additional value during production. 


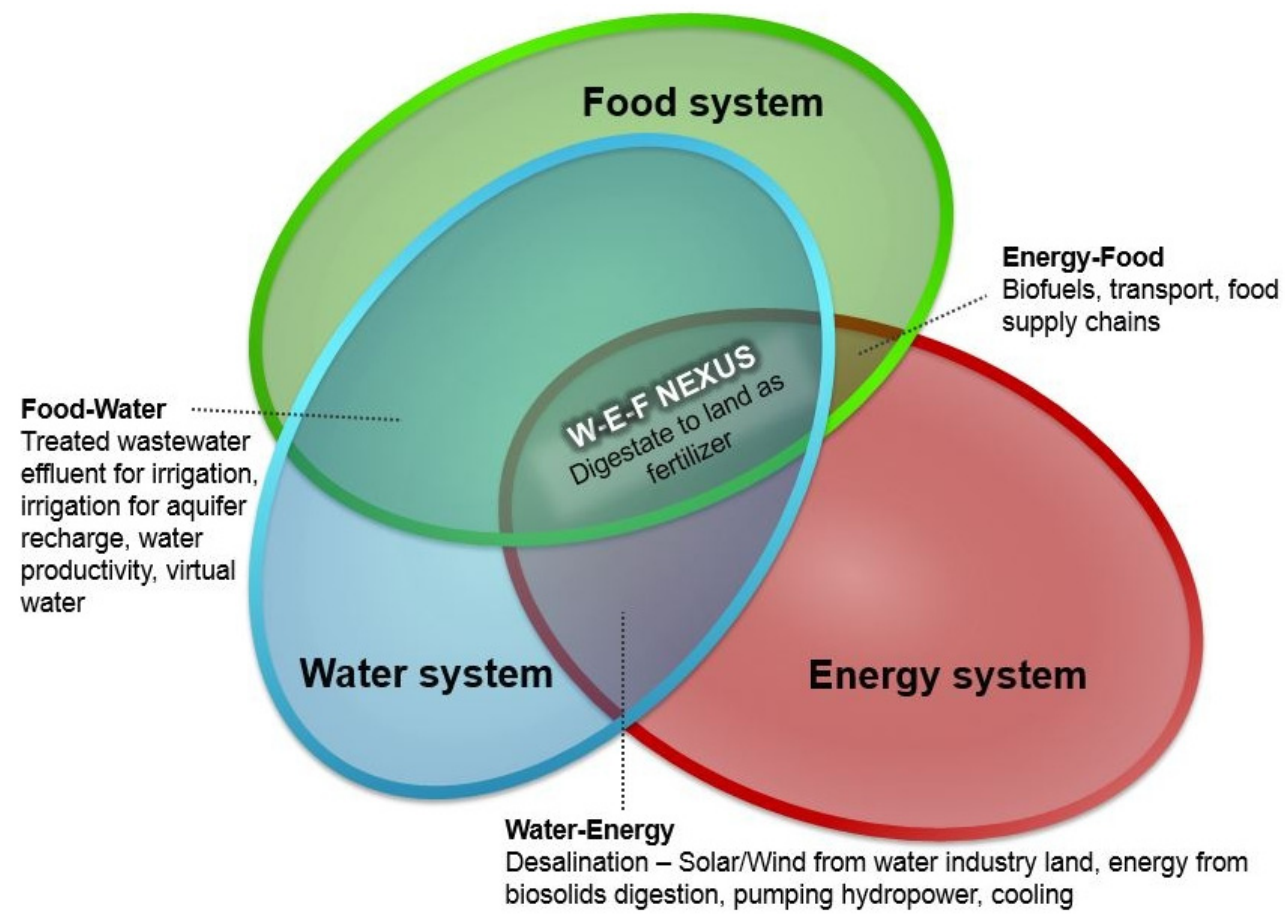

Fig. 4 Sewage sludge application to land as an example of AD application in the nexus of Food, Water and Energy.

Sustainability requires that we do not address single issues in isolation, but instead adopt a systems approach with integrated solutions. If the whole system is considered, a wastewater treatment plant is not only an "end-of-pipe" solution to clean wastewater but can also serve as an energy producer. The interest in biogas is increasing and there is a large unused potential for maximizing the production of biogas, used for both heating and as a fuel in transport applications [30,31]. The water and wastewater sector could benefit from any technological developments and breakthroughs in these areas. Co-digestion is one such breakthrough, and its implementation through an interdisciplinary, integrated and holistic approach could be developed to a real sustainable solution [32].

MBT (mechanical biological treatment) is a generic term for an integrated approach connecting different treatment stages. The success of this process lies in the fact that, it separates biodegradable and non-biodegradable MSW through mechanical means and then it either recycles the materials or uses them for energy recovery as refuse derived fuel [33]. Within such a system opportunities for environmental and commercial benefit can be presented. In the UK, the changing conditions of output markets, as well as planning issues associated with the negative public perception of certain technologies, affect the selection of technologies incorporated in MBT. Some of these drivers are conflicting and have resulted in applications of MBT that are unlikely to maximise commercial and environmental benefit [33], with markets still under development. The lack of European standards for compost quality, and the variation in the quality of the compost-like output reported from country to country, contribute to this. In addition, while, efforts have largely focused on providing incentives for the generation of process outputs (e.g., heat and electricity), little attention has been paid to maximising the benefits from using these outputs. Excess heat, for example, is largely unused and wasted, and so are other materials that can be recovered during the process. Opportunities for using surplus heat can be diverse, especially if taken into account early in the project design stage. Post-development modification is often challenging, due to constraints such as long distances between potential partners and difficulty of establishing 
collaboration between different sectors, among others [3].

In general, barriers to the development of $\mathrm{AD}$ in the UK seem diverse and often interlinked. The risk of interdependence, the sensitivity of information disclosure and coordination issues discourage partnerships required to deliver resource efficiency. For AD to be sustainable, it is necessary to look beyond the boundaries of a single facility to develop synergies and collaborations between relevant stakeholders and regulators. The need for new regulatory frameworks that support development of MBT systems, opportunities for exchanging process outputs among different parties and geospatial planning for identifying suitable locations and mechanisms for material value to previously discarded outputs is clearly identified [3]. Only an interdisciplinary framework that integrates environmental, social and economic aspects in a holistic way, taking into account area, sector and material characteristics and practices, can deliver AD's sustainable potential.

\section{References}

[1] Voulvoulis, N. 2014. "Understanding Systems and Their Complex Interrelationships: a Prerequisite to Solving Environmental Problems." Presented at the Symbiosis International Conference 2014, Athens, Greece.

[2] UNEP (United Nations Environment Programme). 2011. Recycling Rates of Metals-A Status Report. Global Metal Flows to the International Resource Panel.

[3] Iacovidou, E., Vlachopoulou, M., Mallapaty, S., Gronow, J., and Voulvoulis, N. 2013. "Anaerobic Digestion in Municipal Solid Waste Management: Part of an Integrated, Holistic and Sustainable Solution." Waste Management 33 (5): 1035-6.

[4] Iacovidou, E., Ohandja, D. G., and Voulvoulis, N. 2012. "Food Waste Co-digestion with Sewage Sludge-Realising Its Potential in the UK." Journal of Environmental Management 112 (15): 267-74.

[5] Parliament, H.O. 2011. "Anaerobic Digestion." Parliament, H.O.

[6] Postnote. 2007. "Energy and Sewage." The Parliamentary Office of Science and Technology.

[7] Shannon, M. A., Bohn, P. W., Elimelech, M., Georgiadis, J. G., Marinas, B. J., and Mayes, A. M. 2008. "Science and Technology for Water Purification in the Coming Decades." Nature 452 (7185): 301-10.

[8] Preston, F. 2012. "A Global Redesign? Shaping the
Circular Economy." In Energy, Environment and Resource Governance, London: Chatham House.

[9] Wagner, L. 2002. "Materials in the Economy: Material Flows, Scarcity, and the Environment." In US Geological Survey Circular 1221, Denver: U.S. Geological Survey.

[10] Hicks, C., Heidrich, O., McGovern, T., and Donnelly, T. 2004. "A Functional Model of Supply Chains and Waste." International Journal of Production Economics 89 (2): 165-74.

[11] Bridge, G., and Wood, A. 2010. "Less is More: Spectres of Scarcity and the Politics of Resource Access in the Upstream Oil Sector." Geoforum 41 (4): 565-76.

[12] Gordon, R. B., Bertram, M., and Graedel, T. E. 2006. "Metal Stocks and Sustainability." Proceedings of the National Academy of Sciences of the United States of America 103 (5): 1209-14.

[13] Gordon, R. B., Bertram, M., and Graedel, T. E. 2007. “On the Sustainability of Metal Supplies: A Response to Tilton and Lagos." Resources Policy 32 (1-2): 24-8.

[14] Steen, B. 2006. "Abiotic Resource Depletion Different Perceptions of the Problem with Mineral Deposits." The International Journal of Life Cycle Assessment 11 (1): 49-57.

[15] Tilton, J. E., and Lagos, G. 2007. "Assessing the Long-Run Availability of Copper." Resources Policy 32 (1-2): 19-23.

[16] Prior, T., Giurco, D., Mudd, G., Mason, L., and Behrisch, J. 2012. "Resource Depletion, Peak Minerals and the Implications for Sustainable Resource Management." Global Environmental Change 22 (3): 577-87.

[17] Mudd, G. M. 2012. "Key Trends in the Resource Sustainability of Platinum Group Elements." Ore Geology Reviews 46 (August): 106-17.

[18] Miranda, M., and Sauer, A. 2010. Mine the Gap: Connecting Water Risks and Disclosure in the Mining Sector. Washington DC: Will Rogers Institute.

[19] Andersson, B. A., Azar, C., Holmberg, J., and Karlsson, S. 1998. "Material Constraints for Thin-Film Solar Cells." Energy 23 (5): 407-11.

[20] Kleijn, R., and Van der Voet, E. 2010. "Resource Constraints in a Hydrogen Economy based on Renewable Energy Sources: An Exploration." Renewable and Sustainable Energy Reviews 14 (9): 2784-95.

[21] Wadia, C., Alivisatos, A. P., and Kammen, D. M. 2009. "Materials Availability Expands the Opportunity for Large-Scale Photovoltaics Deployment." Environmental Science and Technology 43 (6): 2072-7.

[22] Ostrom, E. 2009. "A General Framework for Analyzing Sustainability of Social-Ecological Systems.” Science 325 (5939): 419-22.

[23] Slade, M. 1992. "Environmental Costs of Natural Resource Commodities: Magnitude and Incidence." In 
Policy Research Working Paper Series, Washington, DC: The World Bank.

[24] Damigos, D. 2006. “An Overview of Environmental Valuation Methods for the Mining Industry." Journal of Cleaner Production 14 (3-4): 234-47.

[25] Dalal-Clayton, B., and Bass, S. 2009. "The Challenges of Environmental Mainstreaming: Experience of Integrating Environment into Development Institutions and Decisions." In Environmental Governance, London: International Institute for Environment and Development.

[26] Freibauer, A. 2011. Sustainable Food Consumtpion and Production in a Resource-Constrained World. Turin: European Commission-SCAR (Standing Committee on Agricultural Research).

[27] Castro-Gomes, J. P., Almeida, M. D., and Pereira Oliviera, L. A. 2006. "Valorization of Mining Waste on Asphalt Pavements of Low Cost." Valorization of Residues Magazine 3 (9): 9-11.

[28] Yellishetty, M. 2008. "Reuse of Iron Ore Mineral Wastes in Civil Engineering Constructions: A Case Study." Resources, Conservation and Recycling 52 (11):
1283-9.

[29] Iranpour, R., Stenstrom, M., Tchobanoglous, G., Miller, D., Wright, J., and Vossoughi, M. 1999. "Environmental Engineering: Energy Value of Replacing Waste Disposal with Resource Recovery.” Science 285 (5428): 706-11.

[30] AEBIOM (European Biomass Association). 2009. "A Biogas Road Map for Europe.” AEBIOM.

[31] NSCA (National Strength and Conditioning Association). 2006. "Biogas as a Road Transport Fuel an Assessment of the Potential Role of Biogas as a Renewable Transport Fuel." NSCA.

[32] Voulvoulis, N. 2012. "Water Sanitation Provision in a Low Carbon Society: the Need for a Systems Approach." Journal of Sustainable Renewable Energy 4 (041403): 1-10.

[33] Defra (Department for Environment, Food and Rural Affairs). "Energy from Waste, a Guide to the Debate." Defra. Accessed November 30, 2014. https:/www.gov.uk/government/uploads/system/uploads/ attachment_data/file/284612/pb14130-energy-waste-2014 02.pdf. 